\title{
Motivos de abandono na prática de ginástica artística no contexto extracurricular
}

CDD. 20.ed. 159

796.41

http://dx.doi.org/10.1590/1807-55092016000401043

\author{
Priscila LOPES \\ Maurício Santos OLIVEIRA** \\ Cíntia Regina de FÁTIMA*** \\ Myrian NUNOMURA ${ }^{* * * *}$
}

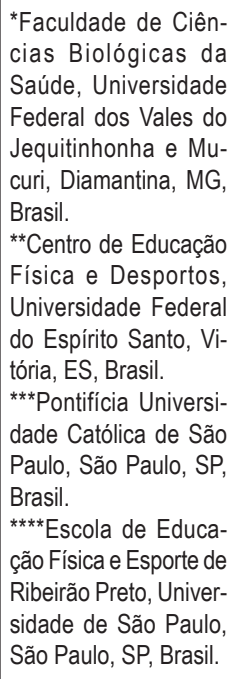

*Faculdade de Ciências Biológicas da Saúde, Universidade Federal dos Vales do Jequitinhonha e Mucuri, Diamantina, MG, Brasil.

${ }^{* *}$ Centro de Educação Física e Desportos, Universidade Federal do Espírito Santo, Vitória, ES, Brasil.

***Pontifícia Universidade Católica de São Paulo, São Paulo, SP, Brasil.

${ }^{* * *}$ Escola de Educação Física e Esporte de Ribeirão Preto, Universidade de São Paulo, São Paulo, SP, Brasil.

\section{Introdução}

Nas últimas décadas, observamos o crescimento pronunciado no oferecimento de atividades extracurriculares no ensino formal que, na opinião de Hansen et al. ${ }^{1}$, são atividades que proporcionam condiçóes e oportunidades para o desenvolvimento pessoal e interpessoal dos jovens.

BASSANI et al. ${ }^{2}$ afirmam que a presença do esporte na escola ganhou destaque "tanto como conteúdo central da Educação Física escolar, quanto prática extracurricular", no qual "os esportes são motivo de canalização de importantes recursos financeiros, materiais e simbólicos nas escolas brasileiras" (p.90).

O Guia Escolas São Paulo ${ }^{3}$ enumera que 68\% das 168 instituiçóes de ensino privado da grande São Paulo oferecem atividades extracurriculares relacionadas ao esporte, as quais contemplam desde a iniciação até o treinamento esportivo para crianças e jovens. Compete citar que, embora estejam relacionadas ao fenômeno esportivo, essas atividades estão inseridas na escola e servem aos mesmos objetivos e funções que são requisitados nas disciplinas obrigatórias e eletivas do currículo. No entanto, elas proporcionam experiências que não estão incluídas nos cursos formais de estudo. Elas permitem que os alunos apliquem os conhecimentos aprendidos em outras aulas e adquiram conceitos de vida democrática $^{4}$ (p.2).

Lopes $^{5}$ cita que entre as modalidades esportivas extracurriculares ofertadas nas escolas da rede privada de São Paulo, a Ginástica Artística(GA) está presente em 26\% delas, o que totaliza 38 instituiçôes.

Desde o final da década de 90 até a atualidade, observamos a maior inserção da GA na sociedade brasileira ${ }^{6}$. CogAn e VIDMAR ${ }^{7}$ citam que as características da modalidade atraem, a cada ano, mais praticantes que, vislumbrados com as apresentaçóes dos atletas do alto rendimento, almejam aprender as habilidades gímnicas. $\mathrm{O}$ ambiente com os aparelhos de grande porte da GA nos convida a experimentar as 
diversas possibilidades de movimento. As sensaçôes, os movimentos e a possibilidade de "lançar-se" ao ar atraem os aspirantes a ginastas.

Esses aspectos são sintetizados nas palavras do ex-ginasta, da antiga União Soviética, Yuri Titov:

Há um instante, logo após você ter soltado as mãos do aparelho, quando você está no ar, livre. Não há sentimento que se compare. Se você está tentando um novo exercício lá, no meio do ar, você saberá se você fez certo. Quando você aterrissa você não precisa de aplauso ou uma medalha - a satisfação está dentro de você. Você conquistou isso e não importa se o ginásio está vazio. Você dominou o medo, superou a dificuldade. Você está repleto de alegria $^{8}$ (p.32).

O sentimento de dever cumprido quando aprendemos um novo elemento gímnico, o reconhecimento quando executamos com perfeição uma série, a conquista de novas amizades e o sentimento de vitória são algumas das recompensas que estão relacionadas com a prática desse esporte.

KLINT e WEIss ${ }^{9}$ afirmam que as ginastas envolvidas na vertente recreativa, nível que se aproxima do contexto de GA abordado nesse estudo, relacionam os motivos de sua participação aos aspectos situacionais, ao senso de competência, ao condicionamento físico obtido pela prática e ao divertimento.

Além das particularidades da modalidade, as crianças e os jovens ingressam na GA por razóes que são comuns ao interesse geral pelo esporte. Weiss e Petlichкoff ${ }^{10}$ sintetizam que os aspectos motivacionais para iniciar e permanecer na prática de esportes estão relacionados à diversão, ao aprendizado de novas habilidades, à vivência de desafios e ao relacionamento social. Mas, apesar desses aspectos positivos e benéficos, muitas crianças e jovens perdem o interesse pelo esporte e, após determinado tempo, abandonam essas atividades ${ }^{11}$.

Em sua coletânea de estudos sobre o tema, Weinberg e Gould ${ }^{12}$ concluíram que, para cada 10 crianças que iniciam uma temporada esportiva, três a quatro desistem antes de concluí-la. A baixa percepção de competência, a falta de foco sobre as metas, os resultados aquém das expectativas e o estresse experimentado pelos jovens atletas são os motivos de desistência mais significativos elencados pelos autores.

Em complementação, KorsaKas ${ }^{13}$ aponta outros fatores associados ao abandono de práticas esportivas e que foram identificados em diferentes estudos, tais como: os conflitos de interesses; o fato de não gostar do treinador; a falta de divertimento; a ênfase excessiva na competição e no rendimento; a sistematização das aulas; o programa de formação esportiva voltado para a especialização precoce; entre outros. Muitos aspectos coincidem com aqueles de BARA FilHo e GARCia ${ }^{14}$ cujo estudo sobre as causas de abandono em práticas esportivas individuais (natação e ginástica artística) de jovens espanhóis, entre 11 e 17 anos de idade, revelou outros fatores, como: a monotonia nos treinos e a necessidade excessiva de tempo de dedicação ao esporte.

Além desses aspectos abordados anteriormente, os pais também podem contribuir para o abandono esportivo. RobBins ${ }^{15}$ relacionou alguns possíveis fatores causadores de estresse em jovens esportistas que, direta ou indiretamente, estariam relacionados aos pais, como: críticas, pressóes e expectativas.

A partir do exposto, verificamos que as razóes do abandono no esporte possuem origem intrínseca ou extrínseca. No modelo de Weinberg e Gould ${ }^{12}$ podemos identificar os fatores intrínsecos como aqueles de ordem pessoal e o extrínseco com ambientais. Massimo e MAssimo ${ }^{16}$ sintetizam que na GA a motivação intrínseca está vinculada às necessidades sentidas pelo ginasta e a extrínseca está relacionada com a satisfação das necessidades ou requisitos impostos, principalmente, pelos pais e técnicos.

Portanto, no presente estudo buscamos identificar a origem e os motivos de abandono da prática de GA no contexto das atividades extracurriculares, apoiando-nos no modelo teórico de motivação intrínseca e extrínseca para a análise e a discussão dos dados. Partimos do pressuposto de que o conhecimento e a compreensão dos motivos que resultam no abandono podem auxiliar os treinadores a atuarem cada vez mais em direção aos interesses e às necessidades dos praticantes. E, assim, tornar a experiência esportiva mais significativa, eficaz e prazerosa e que pudesse contribuir para o engajamento de crianças e jovens no esporte.

Embora a literatura contemple o abandono esportivo, Bara Filho e GARCiA ${ }^{14}$ concluíram que a maioria das pesquisas foi realizada em países como Estados Unidos, Inglaterra e França, o que demonstra a lacuna de investigaçôes em países latinos. Ademais, os autores apontam para a necessidade de estudos atuais e que sejam desenvolvidos em diferentes realidades geográficas e socioculturais, pois os interesses dos jovens são diversos e podem resultar em diferentes motivos de abandono a depender do contexto. Em corroboração, CARMo et al. ${ }^{17}$ atentam para esses fatores e mencionam a carência de estudos dentro da realidade esportiva brasileira. 


\section{Método}

Utilizamos a entrevista semiestruturada como instrumento de coleta que, segundo TrIVIÑos ${ }^{18}$, consiste em um dos principais meios para a obtenção de dados em pesquisas de natureza qualitativa. $\mathrm{Na}$ opinião do autor, esse método de entrevista valoriza a presença do investigador e oferece aos sujeitos a liberdade e a espontaneidade necessárias para o fluxo de informações, o que enriquece o processo de investigação.

Foram entrevistadas 25 meninas praticantes de GA, entre 11 e 17 anos de idade, distribuídas em seis colégios da rede particular da Grande São Paulo e com registro de histórico de abandono na modalidade por determinado período. As entrevistas foram realizadas individualmente, gravadas e transcritas integralmente.

Para o tratamento dos dados optamos pela técnica de Análise de Conteúdo proposta por BARDin ${ }^{19}$. Ressaltamos que a Análise de Conteúdo é entendida como um conjunto de técnicas de análise das comunicaçóes visando obter, por procedimentos sistemáticos e objectivos de descrição do conteúdo das mensagens, indicadores (quantitativos ou não) que permitam a inferência de conhecimentos relativos às condiçóes de produção/percepção (variáveis inferidas) destas mensagens (p.37).

Segundo a autora, os dados são codificados, classificados e categorizados, o que possibilita a análise do conteúdo que emerge das mensagens e que se referem aos pontos de interesse para a pesquisa.

As categorias foram elencadas a partir de um tema norteador. Enfatizamos que não focamos na análise quantitativa dos fatores que motivaram as ginastas a abandonarem a prática da GA, mas no conteúdo das mensagens.

O estudo foi aprovado em Comitê de Ética (CEP03709/EEFE/26032009).

\section{Resultados}

Após a codificação dos dados, identificamos a categoria "Motivos de Abandono da GA" constituída

por duas subcategorias e as respectivas Unidades de Registro, conforme o QUADRO 1.

QUADRO 1 - Resultado sobre os motivos de abandono da GA.

\begin{tabular}{|l|c|}
\hline \multicolumn{2}{|c|}{ Categoria: Motivos de abandono da prática de GA } \\
\hline Subcategorias & Unidade de registro \\
\hline Motivos intrínsecos & Mudança de interesses \\
\hline \multirow{4}{*}{ Motivos extrínsecos } & Problemas de saúde/lesôes \\
\cline { 2 - 2 } & Excesso de atividades escolares \\
\cline { 2 - 2 } & Falta de amizades na turma \\
\cline { 2 - 2 } & Falta de afinidade com treinador \\
\cline { 2 - 2 } & Dependência dos pais \\
\hline
\end{tabular}

\section{Discussão}

No QUADRO 1, observamos que o único motivo intrínseco citado na pesquisa está vinculado à mudança de interesses. Massimo e MAssimo ${ }^{16}$ e JoHNS et al. ${ }^{20}$ afirmam que a pressão dos pares e a vida social são dois fatores que desencadeiam o abandono na GA. Os autores citam o conflito entre o esporte e as atividades sociais, entre as quais: cinema, festas, danças e outras atividades associadas ao estágio de vida, conforme verificamos no depoimento de A12:
Tem dias que eu prefiro muito mais ficar conversando com meus amigos no poli, ir no cinema, ficar andando no shopping. Pra mim as vezes é bem mais gostoso do que essa rotina de GO.

A ginasta A12 é adolescente e passa por um período de mudanças físicas, psicológicas e sociais ${ }^{21}$. É coerente que o fato gere conflitos de interesses, como no caso deste estudo, entre a atividade esportiva e a vida social. Consideramos a mudança 
de interesses como um motivo intrínseco pelo fato do abandono da prática esportiva partir de uma decisão interna sem interferência externa ou do ambiente.

Apoiados na literatura, ponderamos que a construção de um ambiente que atenda aos interesses e às necessidades dos adolescentes auxiliaria na diminuição da evasão motivada por esse aspecto, principalmente, se o treinador privilegiar atividades que contribuam para o estabelecimento de vínculos entre os pares no contexto esportivo. Gould et al. ${ }^{22}$ afirmam que o desenvolvimento de amizades e a atmosfera social colaboram para a permanência de atletas no esporte.

Sobre os motivos extrínsecos, destacamos os problemas de saúde/lesôes como a unidade de maior emergência no discurso das ginastas:

...em outubro do ano passado, eu tive que fazer uma cirurgia no pé... (A1).

Parei porque eu tive uma tendinite no tornozelo e eu comecei a fazer fisioterapia (A13).

...esse ano eu fiquei quatro meses parada, porque eu estou com hérnia de disco (A16).

...eu tive que parar ano passado, porque eu tive uma queda (A24).

Massimo e Massimo ${ }^{16}$ ressaltam que a possibilidade de sofrer algum tipo de lesão faz parte do contexto da GA. E, a sua ocorrência poderia causar algum trauma na prática da modalidade. E, consequentemente, ocasionar eventual afastamento do ginasta bem como interferir na motivação para a participação futura em outras modalidades. Pois, "uma ginasta que tem número excessivo de acidentes, que eventualmente poderiam ser graves, será muito consciente do preço para continuar" (p.161).

No entanto, apesar do potencial de risco de lesão, a prática da GA é consideravelmente segura desde que seja devidamente orientada e respaldada por medidas preventivas $^{23}$. Os treinadores devem estar atentos às possíveis causas de lesóes e refletir sobre como a modalidade é desenvolvida no ambiente extracurricular.

A falta de amizades no grupo foi outro motivo enunciado nas entrevistas, conforme A19: "Porque na ginástica artística eu não tinha muita amiga, né (A19)". Weinberg e GoulD ${ }^{12}$ citam que os jovens apreciam o esporte pelo seu potencial de encontrar os amigos e fazer novas amizades. Sabemos que as relaçóes entre os pares no contexto esportivo podem ser tanto positivas como negativas.

Segundo WeIss et al. ${ }^{24}$, os fatores positivos abarcam o companheirismo, o aumento da autoestima, o comportamento pró-social, a intimidade e a lealdade. Esses são aspectos que favorecem e promovem a motivação e a participação em atividades esportivas. Por outro lado, os aspectos negativos nas relações entre os pares seriam situaçôes de conflito, ausência de afinidade, traição e inacessibilidade. No caso de A19, a dificuldade em se integrar ao grupo culminou com a sua saída da prática da modalidade. Um fator discutido no estudo de Fraser-ThOMAS et al..$^{25}$ que cita o impacto negativo da falta de amigos no ambiente esportivo o qual contribui para a saída prematura de alguns jovens esportistas.

A falta de afinidade com o treinador foi ressaltada como outro motivo de afastamento por algumas praticantes:

É, eu comecei no colégio uns anos antes, né. Só que aí eu não gostei muito, né, por causa que a professora não era a X, era uma outra (A20).

Eu entrei um ano... daí eu entrei na 5a série, mas daí a professora não era a mesma (A22).

Sabemos que o engajamento dos jovens esportistas é influenciado pela postura dos treinadores ${ }^{26}$.

Moraes et al. ${ }^{27}$ lembram que o conhecimento dos motivos que determinam a escolha do esporte pelo atleta é fator primordial para o sucesso do relacionamento entre treinador e atleta. E, consequentemente, favorece a permanência dos indivíduos na prática esportiva. Massimo e Massimo ${ }^{16}$ refletem que a maioria dos ginastas está à procura de um ambiente onde aprendam de forma segura, sintam-se bem e no qual desenvolvam bons relacionamentos interpessoais. Mas, alguns ginastas procuram "um mundo de sonhos no qual fazer ginástica” (p.74), ou seja, um ambiente que atenda a todas as suas expectativas e, principalmente, que náo se frustrem. Independente do perfil do treinador, esses ginastas frustrarão, pois os obstáculos e desapontamentos fazem parte da formaçáo esportiva. Compete ao treinador buscar o equilíbrio e oferecer atividades que proporcionem o sentimento de competência e que se adeque ao contexto das atividades extracurriculares, pois, muitas vezes, o modelo do esporte de alto rendimento para adultos é suplantado para esse contexto.

A dependência dos pais para se deslocar até a prática esportiva no contraturno escolar interferiu, também, no afastamento das crianças e dos jovens das atividades, conforme os relatos de A20 e A23: esse horário é muito difícil pro meus pais, porque eles trabalham lá em SP e eu moro muito longe daqui (A20).

era muito longe, aí minha mãe começou a trabalhar e não tinha como ela ir me buscar (A23). 
Hoeferet al. ${ }^{28}$ ressaltam que o provimento de transporte para a atividade esportiva é uma forma de apoio físico e social, no qual os pais atuam como facilitadores das oportunidades esportivas. Em complementação, WeIss e Hayashi ${ }^{29}$ e STEIN et al. ${ }^{30}$ citam que o transporte para os treinos e competiçóes é fundamental para o engajamento das crianças e jovens na prática esportiva, principalmente, devido à faixa etária que gera maior dependência dos pais ${ }^{31}$.

Outro motivo para o abandono está relacionado com o excesso de atividades escolares: "Aí começou semana de prova de recuperação, depois semana de feriado, agora é semana de prova" (A12). As demandas e a pressão da vida escolar influenciam na decisão de se retirar da $\mathrm{GA}^{20}$. Essa opinião é compartilhada por Massimo e Massimo ${ }^{16}$ que relatam que a pressão associada às atividades escolares é uma das razóes para o abandono prematuro da modalidade. No estudo desenvolvido por BARA Filho e Garcia ${ }^{14}$, os autores reforçam essa visão e pontuam que a pressáo para se dedicar aos estudos consiste no motivo de maior incidência para o abandono esportivo.

Quando a jovem ginasta depara-se com dificuldades nos estudos, muitas vezes, opta por abdicar das atividades esportivas, pois organizar a prática da GA, os estudos e contemplar as próprias expectativas, com relação a ambos é um verdadeiro desafio ${ }^{16}$. Além disso, os pais podem influenciar na decisão de abandonar a modalidade ao exigir bom desempenho escolar ou determinar o afastamento como punição por resultados abaixo das expectativas.

Após a discussão dos dados, KorsaKas ${ }^{13}$ aponta que o modelo de esporte imposto às crianças e jovens é semelhante ao de adultos e não atinge aos objetivos ou expectativas desse público. Ainda de acordo com a autora, as mudanças e as adaptaçóes existentes não são suficientes para evitar o alto índice de abandono que ocorre nessa fase.

O fato se deve, em parte, ao despreparo e à falta de conhecimento sobre a pedagogia do esporte entre os profissionais de educação física, fator que pode contribuir com o abandono esportivo ${ }^{32}$. As práticas esportivizadas, a fragmentação de conteúdos, a prática repetitiva de gestos técnicos e a especialização precoce constituem alguns dos problemas da iniciação esportiva enunciados por PAes e BALBINO ${ }^{32}$.

Bara Filho e GARCIA ${ }^{14}$ acreditam que o treinador poderia influenciar diretamente nos fatores de abandono dos praticantes. E, para evitar tal situação, sugerem estratégias que eliminariam a monotonia, a falta de motivação, o esgotamento e a dedicação excessiva.
Ressaltamos que os fatores intervenientes no abandono devem ser analisados de forma qualitativa e, por isso, ROBERTSON ${ }^{33}$ acredita que o tema ultrapasse a mera análise estatística. $\mathrm{O}$ autor destaca a complexidade do tema, pois as origens e os motivos são diversos e poderia haver sobreposição e, em alguns casos, a combinaçáo entre eles. Há preocupaçáo pronunciada entre treinadores e psicólogos com esse fenômeno, pois, além de perder atletas, possíveis implicaçóes dessa saída poderiam repercutir no futuro desses jovens.

No decorrer do estudo, observamos que os motivos que influenciaram o abandono esportivo são multifatoriais. Isso aumenta a dificuldade em estabelecer estratégias que diminuiriam a evasão. No caso da GA, Cogan e VIdmar ${ }^{7}$ acrescentam que as dificuldades e as características próprias da GA poderiam catalisar o abandono. O sentimento de derrota, a falha em um evento competitivo, a dificuldade em realizar um elemento nas aulas, o cansaço físico, a falta de reconhecimento, as lesões e o medo exemplificam essa questáo.

Os motivos que contribuíram para o abandono entre nossos sujeitos coincidem com aqueles apresentados por Massimo e Massimo ${ }^{16}$ e Johns et al. ${ }^{20}$ que também estudaram ginastas. Os aspectos divergentes relacionam-se à intensidade de treino, ao nível de treinamento e ao tempo de comprometimento que são fatores mais próximos do setor competitivo. Destacamos que investigamos praticantes de GA nas atividades extracurriculares, no ambiente escolar, onde a frequência, a intensidade e o empenho nas aulas são menores se comparado ao treinamento de alto nível ${ }^{34}$.

Por fim, ressaltamos as ideias de Massimo e Massimo $^{16}$ quando citam que o treinador deve desenvolver atividades que sejam atraentes e motivadoras, as quais deveriam estar apoiadas em uma filosofia de trabalho ${ }^{35}$ que atenda aos interesses dos alunos e da instituição. Dentre as estratégias, poderíamos sugerir: a criação de eventos sociais paralelos; o estabelecimento de acordos e compromissos; o diálogo sobre a fase de adolescência; o auxílio no estabelecimento de metas; a distribuição de tarefas e de responsabilidades para estimular o comprometimento nos treinos; o envolvimento dos pais nas atividades de forma que entendam a rotina e o desempenho dos filhos; entre outros.

Consideramos que seja imprescindível conhecer e compreender os motivos que levam os jovens à prática esportiva ${ }^{36}$, pois, assim, poderíamos evitar os fatores que incidem sobre o momento do abandono e as consequências negativas que comprometeriam o interesse pelo esporte. Corroboramos Bara Filho e 
GARCIA ${ }^{14}$ que ressaltam que os resultados encontrados em estudos sobre abandono poderiam servir como parâmetros, mas devemos estar atentos aos contextos, pois cada atleta está vinculado à realidades distintas e, consequentemente, os motivos para o abandono da prática esportiva também difeririam.

\title{
Nota
}

A autora Cíntia Regina de Fátima é doutoranda do Programa de Pós-graduação em educação: psicologia da educação, Pontifícia Universidade Católica de São Paulo, São Paulo, Brasil.

\begin{abstract}
Reasons for dropout of the practice of artistic gymnastics in the extracurricular context

Sport is the main option for physical activity among children and youth. Despite the great interest of this group with regard to sports practices, the literature indicates a high dropout rate. Motivated by this conjuncture, the objective of this study was to verify the reason for dropout, more specifically, in Women Artistic Gymnastics (WAG) within the context of extracurricular activities. We interviewed practitioners of WAG who have a record regarding withdraw of this sport for a certain period of time. For the data treatment, the content analysis proposed by BARDIN was chosen. We found that intrinsic and extrinsic factors are linked to the process of dropout of this sport. However, the extrinsic factors overlapped those intrinsic, evidencing that the environment and situational and interpersonal conditions exert greater influence on the withdrawing of the gymnasts. Thus, we emphasize the importance of the coaches' attention to these aspects in order to ensure that activities meet the needs and desires of gymnasts.
\end{abstract}

KEY WoRDS: Youth-sport; Parents-support; Artistic gymnastics; Motivation.

\section{Referências}

1. Hansen D, Larson R, Dworkin J. What adolescents learn in organized youth activities: a survey of self-reported developmental experiences. J Res Adolesc. 2003;13:25-56.

2. Bassani JJ, Torri D, Vaz AF. Sobre a presença do esporte na escola: paradoxos e ambiguidades. Movimento. 2003;9:89-112.

3. Guia Escolas São Paulo 2008. São Paulo: Educacional Marketing; 2008.

4. Lunenburg FC. Extracurricular activities. Schooling. 2010;1:1-4.

5. Lopes P. Motivação e ginástica artística formativa no contexto extracurricular [dissertação]. São Paulo (SP): Universidade de São Paulo, Escola de Educação Física e Esporte; 2009.

6. Nunomura M. Ginástica artística. São Paulo: Odysseus; 2008.

7. Cogan KD, Vidmar P. Sports psychology library: gymnastics. Morgantown: Fitness Information Technology; 2000.

8. Goodbody J. The illustrated history of gymnastics. Londres: Stanley Paul; 1982.

9. Klint KA, Weiss MR. Dropping in and out: participation motives of current and former youth gymnasts. Can J Appl Sport Sci. 1986;11:106-14.

10. Weiss MR, Petlichkoff LM. Children's motivation for participation in and withdrawal from sport: identifying the missing links. Pediatr Exerc Sci. 1989;1:195-211.

11. Scalon RM. A psicologia do esporte e a criança. Porto Alegre: EDIPUCRS; 2004.

12. Weinberg R, Gould D. Fundamentos da psicologia do esporte e do exercício. Monteiro MC, tradutora. 4a ed. Porto Alegre: Artmed; 2008.

13. Korsakas P. O clima motivacional na iniciação esportiva: um estudo sobre a prática pedagógica e os significados de esporte e educação [dissertação]. São Paulo (SP): Universidade de São Paulo. Escola de Educação Física e Esporte; 2003. 
14. Bara Filho MG, Garcia FG. Motivos de abandono no esporte competitivo: um estudo retrospectivo. Rev Bras Educ Fís Esporte. 2008;22:293-300.

15. Robbins JE. Reducing stress: techniques for parents, coaches, and athletes. SpotlightonYouthSports. 2001;25:1-3.

16. Massimo J, Massimo S. Gymnastics psychology: the ultimate reference guide for coaches, athletics and parents. New York: Morgan James; 2013.

17. Carmo JVM, Matos FO, Ribas PR, Miranda R, Bara Filho MG. Motivo de início e abandono da prática esportiva em atletas brasileiros. HU Rev. 2009;35:257-64.

18. Triviños ANS. Introdução à pesquisa em ciências sociais: a pesquisa qualitativa em educação. São Paulo: Atlas; 1987.

19. Bardin L. Análise de conteúdo. Reto LA, Pinheiro A, tradutores. 4a ed. Lisboa: Ediçôes 70; 2006.

20. Johns DP, Lindner KJ, Wolko K. Understanding attrition in female competitive gymnastics: applying social exchange theory. Sociol Sport J. 1990;7:154-71.

21. Mussen PH, Conger JJ, Kagan J, Huston AC. Desenvolvimento e personalidade da criança. Mourão Netto MS, tradutora. 4a ed. São Paulo: HARBRA; 1977.

22. Gould D, Feltz D, Weiss MR. Motive for participation in competitive youth swimming. Int J Sport Exerc Psychol. 1985;16:126-40.

23. Nunomura M. Segurança na ginástica artística. In: Nunomura M, Nista-Piccolo V, organizadoras. Compreendendo a ginástica artística. São Paulo: Phorte; 2005. p.59-75.

24. Weiss MR, Smith AL, Theeboom M. That's what friends are for: children's and teenagers' perceptions of peer relationships in the sport domain. J Sport Exerc Psychol. 1996;18:347-79.

25. Fraser-Thomas JL, Côté J, Deakin J. Youth sport programs: an avenue to foster positive youth development. Phys Educ Sport Pedagogy. 2005;10:19-40.

26. Nunomura M, Oliveira MS, Roble OJ, Carbinatto M. Ginástica artística competitiva e a filosofia dos técnicos. Motriz. 2012;18:678-89.

27. Moraes LC, Salmuski D, Noce F. Fatores motivacionais para prática do judô. In: Greco PJ, Salmuski D, Caran Júnior E, organizadores. Temas atuais em educação física e esportes. Belo Horizonte: Healthet; 1997. p.125-43.

28. Hoefer WR, Mckenzie TL, Sallis, JF, Marshall, SJ, Conway TL. Parental provision of transportation for adolescent physical activity. Am J Prev Med. 2001;21:48-51.

29. Weiss MR, Hayashi CT. All in family: parent-child influences in competitive youth gymnastics. Pediatr Exerc Sci. 1995;7:36-48.

30. Stein, GL, Raedeke TD, Glenn SD. Children's perceptions of parent sport involvement: it's not how much, but to what degree that's important. J Sport Behav. 1999;22:591-601.

31. Uva, JES. Aspectos a considerar na relação com os pais dos atletas: o papel dos pais no atletismo para jovens. Treino Desport. 2005;3:34-42.

32. Paes RR, Balbino HF. Pedagogia do esporte e os jogos coletivos. In: Rose Júnior D, organizador. Esporte e atividade física na infância e na adolescência: uma abordagem multidisciplinar. Porto Alegre: Artmed; 2002. p.73-84.

33. Robertson I. Developing children and youth through sport. Gymnastics Coach. 1987;6:13-5.

34. Arkaev L, Suchilin N. Gymnastics: how to create champions. Oxford: Meyer \& Meyer Sport, 2004.

35. Salgado M. Para nós, jovens treinadores. Treino Desportivo. 1999;Especial 2:67-71.

36. García FG. O burnout em jovens desportistas. In: Becker Júnior B, organizador. Psicologia aplicada à criança no esporte. Novo Hamburgo: FEEVALE, 2000. p.58-82.

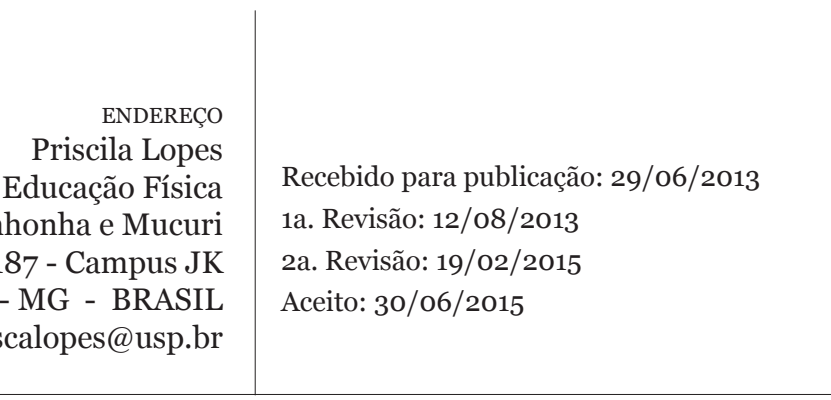

